\title{
Pattiann Rogers - Teaching a Sea Turtle Suddenly Given the Power of Language, I Begin by Saying:
}

\section{This green translucent continuance}

Through which you turn and function, rolling and twisting,

Which fluctuates in darkness, which pulses and pushes

Insistently against your forehead and your belly

And your genitals, to the top of which you must rise for light,

For breath, is called 'The Great Sea.'

And by these fingers, of which you have none, I am tracing

The curve of your horned beak, tracing your flippers

Intricately scaled in canvas, moving down over the wooden

Knobs of your back, down to the leather prick of your tail,

Tracing all the boundaries of that which is called 'self,'

'Great Turtle of the Great Sea.'

And you must try to remember that heavy, ponderous,

Slow-shifting silence which was everything you didn't know you knew

Before your voice. Say 'silence' and listen.

Say 'silence.'

And your motion is called 'gliding, soaring

Propulsion of self' and the passing, one after another,

Of seaweed clusters and floating eels and rainbow wrasse

And scattered obelia is called 'time.' And the direction

Toward which you move is called 'land.' Say 'compelled,'

Say 'driven,' say 'recognition of compulsion.'

Understand how you will eventually make the facts of the earth By the hard drag-marks of your body over the dunes,

How by interference you will make the aggravated existence of bark

And grit and rut and sandbur. Say 'egg,' say 'begat,' say 'birth

In the warm sandy loam.' Say 'birth by the nearest silver egg

Buried in the sky.' Say 'invisible glass turtles pulling up

The black beaches above, leaving in the night

The scattered glow of their daring eggs.'

Say 'fancy.' 
Here at the bottom of the sea, beneath the pock-marked Boulder, beside the extending and withdrawing feathers Of the polyps, in the definite turn and focus

Of your reflective eye, here is where you must begin now To be engaged in the making of your brain, each new word Bringing a salt-pulsing neuron simultaneously into existence. Listen, I am telling you, it is from the awareness

Of this precise moment

That the creation of yourself begins. 